\title{
BASM after the Institute
}

How will BASM, as the national representative membership organization in sports medicine, respond to the foundation of the National Sports Medicine Institute this summer?

The prime functions of the NSMI are to promote sports medicine and all necessary education to that end.

BASM's limitations in education reflect the inevitable shortages of money and manpower affecting any voluntary body seeking to serve a professional coordinating, not to say regulatory, function. BASM's relatively modest income does not permit full office support and any busy professional who volunteers for office knows that his time and energy are always too limited for the causes he espouses. Hence BASM's long campaign for 'official' recognition; its first deputation to the original Sports Council was rebuffed in the early seventies! We have raised our subscriptions as fast as our membership could tolerate, inevitably losing some members and, determined to advance, have streamlined some of our office functions and reformed the Journal.

However, the broader time-scale is inevitably against such evolution. We believe that the Sports Council chose to launch the initiative which culminated in the NSMI because the demanding voice of sport could no longer be ignored. To its surprise, it found BASM and the medical professions more than willing to cooperate fully and, indeed, impatient for action. Despite the Sports Council's NSMI Foundation Working Party's non-representative status, its conclusions have been accepted by all parties, including BASM's recent Extraordinary General Meeting, without dissent or delay.

Part of this new hope for the NSMI lies in the London Sports Medicine Institute's 5-year life. Its existence showed how far even a local body could go if backed by money and a proper office. Its budget of roughly $£ 150,000$ per annum allowed it to host offices, a library and a laboratory. It rapidly became a focus for sports medicine enquiries and information as well as a plethora of postgraduate courses and lectures. It also allowed BASM's Education Officer a home base.

Far from being squeezed, BASM thrived. The past 5 years have seen a doubling of introductory courses, the introduction of the Advanced Course programme, uniquely designed in weekend modular form, the strong representation of BASM in the pioneering Diploma in Sports Medicine of the Society of Apothecaries, the reform of the Journal and a steady growth in both subscriptions and membership. The residential weekend AGMs were established and BASM has steadily become more widely recognized as the voice of sports medicine. We would argue that these developments were made possible by BASM's productive symbiosis with the LSMI.

Thus, with the expiry of LSMI's lease on sports medicine history, the stage is set for the natural evolution of LSMI to NSMI. Symbiosis can now occur with greater confidence from the Sports Council's recognition and funding of sports medicine. As BASM has developed over the past 5 years, so it can use the opportunities for renewed growth in the future.

Perhaps, as we look forward to another quinquennium, we might find an established national reference centre for sports medicine, complete with library, information sheets and publications. More educational programmes, ever more widely spread geographically, will cater for the medical professions and a commercially sponsored lay programme might be following overseas precedents. A corpus of sports medicine knowledge will be accepted by the medical schools in an era of health and fitness promotion and NSMI, building with BASM on BASM's sports clinic classification, will be defining professional standards and - who knows? - publishing the sports medicine register of certified specialists.

NSMI is here to be professional and business-like; it will have to fund-raise towards financial independence. BASM might at last be freed from carrying single-handed and at its own expense a specialty's entire intellectual impedimenta and be able to establish its new identity as a thriving membership organization. Can BASM, that is to say, that body of members who are BASM, rise to this long overdue challenge? 